\title{
Computer Aided Instruction for Literature Courses Teaching ${ }^{(1)}$
}

\author{
Jing Guo ${ }^{\mathrm{a},{ }^{*}}$, Jianping Zheng ${ }^{\mathrm{a}, * 2}$ \\ ${ }^{a}$ School of Literature and Art, Southwest University of Science and Technology, Mianyang, China
}

\begin{abstract}
A majority of domestic universities currently possess conditions of carrying out computer aided instruction, however, most of them are immersed in pure applications of multimedia classroom systems. In such application environment, teachers of literature courses generally have bias on understanding of multimedia, thus they pay more attentions to application of multimedia teaching tools and ignore the effective combination of multimedia technology and literature courses with its own characteristics. Literature courses primarily allow students to capture the beauty of Chinese language and its styles through permutations and combinations of them, and then enjoy pleasure of character plots, deep thoughts and feelings and so on. Based on this understanding, computerassisted instruction should reasonably arrange proportion of multimedia elements: text, images, audio, video and others. Meanwhile, education of magnetic personality of teachers and predominance of teachers during teaching process should not be neglected. At last but not least, proper body language, fine grasp of the classroom rhythm and suitable display of multimedia elements can dramatically improve the effectiveness of delivery, and then achieve the purpose of humane education.
\end{abstract}

Index Terms: Literature Courses; Computer Aided Instruction; Multimedia; Courseware

(C) 2011 Published by MECS Publisher. Selection and/or peer review under responsibility of the International Conference on E-Business System and Education Technology

\section{Introduction}

Computer aided instruction (CAI) encompasses a broad range of computer technologies that supplement classroom learning environment and can remarkably increase a student's access to information [1]. CAI combines this application of multimedia, hypertext, computer technology, artificial intelligence, knowledge base and such computer technology, overcoming traditional teaching methods of dullness and singleness, effectively shortening learning time and improving teaching quality and efficiency, thus to achieve optimal teaching objectives. Due to the existence of these obvious advantages, CAI is increasingly used for computer education in China. In our country, there were almost all colleges, secondary and primary schools deploying CAI education conditions, even in remote mountainous areas with limited resources, educators have also been aware of aforementioned superiorities of CAI. At the same time, however, with the deepening of understanding to CAI and practicing of teaching activity, educators have already get rid of the initial stage of blind fanaticism

\footnotetext{
${ }^{(1)}$ This work has been supported, in part, by Education Reform and Research Project of province ( P09225 ).

Corresponding author:

| E-mail address: ${ }^{* 1}$ guojing@ @ swust.edu.cn; ${ }^{* 2}$ zhengjianping@swust.edu.cn
} 
to CAI. And even there existed in some literature courses that a return voice of traditional teaching methods was heard. It has been only for few years since CAI appeases in China, even in the America it occurred only before fifty years. So for such a new concept, it is very normal for existence of criticism or rational reasoning. With the development of information technology and deeply understanding for the computer language, it is reasonable to believe that, in the teaching of literature courses, we can utilize CAI to achieve the desired targets.

\section{Problems in Computer Aided Instruction Applications}

CAI has application environment of specific implementation, one of them multimedia classroom system is the most basic component. Main function of multimedia classroom is to utilize a classroom equipped with computers and large screen projection device for showing multimedia courseware. Especially, if you access the campus network, you can also login some various teaching sites and a variety of teaching resource library, and make VOD or download multimedia courseware presented locally. In general, hard facilities of multimedia classroom include computers controlled by speaker teacher and corresponding projection equipments, as well as a variety of teaching resources.

Another type is interactive classroom which not only realizes VOD of multimedia courseware but also facilitates to communicate between teacher and students. Specifically speaking, in interactive multimedia classroom, teacher flexibly controls multimedia computer playing desired courseware by oneself, and thus displays the same content with main computer on every screen of computer used by students. Therefore, speaker teacher can surveillance practical case of students with help of control platform of host computer. More importantly, every student can make necessary exchange with teacher according to their actual situation by means of own computer. As a rule, equipments of interactive multimedia classroom comprise host computer utilized by teacher, computer used by students, controlling devices of multimedia teaching, etc.

At present, vast majority of universities are equipped with multimedia classroom systems, thus teacher is prone to copy traditional teaching content to courseware through CAI writing system (PowerPoint software is commonly used). During courseware production, in most instances, word texts are directly pasted to of bank pages of PowerPoint, or even better words are hyperlinked with related pictures, audio, video information, etc. It has no difference from playing classroom blackboard in traditional teaching mode in the PowerPoint. In fact, emergence of this situation is associated with understanding bias of teachers upon main function of courseware. Many teachers think that main task of courseware is to present teaching content through multimedia form, which neglects grasp of teaching content and objectives. Understanding bias on its main functions will naturally lead to make too much focus on presentation of media functions during production of courseware for teachers, and lack interlink and verification among media features and course contents. The resulting is that in teaching process teacher might operate computer for animatedly displaying elegant pictures, beautiful animation and attractive audio and video information, which appears a form or surface of excitement for current CAI. In the interactive multimedia classroom, teacher can make a targeted response to specified case of some students, really achieving interaction among students through computer medium. However, due to higher price of cost of interactive multimedia classroom system than multimedia classroom system, it is not popularly used in domestic many schools.

\section{Issues of Teaching over Computer Aided Instruction}

"Information dissemination of traditional teaching methods is a two-way exchange between teachers and students, in which teachers transmit information to students through language, blackboard, chalk, flip charts, physical and other media, and in which students receive information through these media too. Now introduction of multimedia in teaching, which makes medium increased dissemination of information, that is, more channels of students receiving information." [2]. In multimedia classroom system of literature courses, if one appropriately and reasonably utilizes media language and produces courseware closely linked to teaching objectives, teaching can completely achieve good results. With help of multimedia technology, teachers can 
make teaching contents being stereoscopically presented. Rich audio-visual perception of environment and provision of a wide range of vector text content are shown, which greatly improve effect of multi-dimensional perception of teaching content, and change abstract to imaginary. In addition, CAI can also dilute factors of boring or rigid probably existed during tasteless explaining, thus creating a relaxed and fun learning atmosphere.

As for current literature curriculum, it is not often seen of achieving these states of courses teaching. In process of literature curriculum teaching, instructor aims to present vivid, intuitive and three-dimensional feelings of plane language and text, playing data related to literature works, such as picture, animations, and audio or video files. "Contents of course are neglected by gaudy animations or movies, thus causing information content of multimedia teaching oversized finally, and turning the traditional 'person pour' teaching into the modern 'computer pour' teaching; either information is in disorder or computer screen is shown with multi-color, at last it is similar to watch movie for students, and superiority of multimedia teaching could not manifested completely.'[3]. There is no denying that involvement of these media language can enrich classroom teaching. However, we should rationally face new challenge of more involvements of media language into literature courses teaching which mainly present text writing.

\subsection{Multimedia information equals to literature works itself}

Since dynamic and stereoscopic video information is more appealing than static and planar text language, in frontier of literature drama and corresponding adapted movies, students tend to watch movies, and what is more, equate mutually both them. Consequently plots of stories are used to analyze and understand text drama. If instructor has shown feeling on some literary work during delivering a lecture, plots of related adapted movies are probably linked into this process. And no mistake, it intensifies error recognition about literature text and understanding on movies adapted by text drama.

From point of creative view, any movie drama adaptation based on literary texts can be reasonable to make adaptations under context of plots need. Literature works, film and movie, after all, belong to different types of art. Literature creates artistic character with language medium and means, reflecting real life, exhibiting people's spiritual world. In fact, it is a flat and static art. The movie is integrated art, static art and dynamic art, time art and space art, plastic art and rhythm art, it has multiple types of manifestation. Two arts have different specific manifestations, which can lead to reasonable adaptation according to features of movie art when pure texts are revised. However, due to limited recognition ability of students, if teachers make none communications with students in the classroom, after movie played, directly analyze characters and ideological content, which is more likely to introduce students to traps: literary works being equal to movie plots. More serious consequence is that our students abandon study of literary texts since then, and completely convert to understand works through movie plots.

Moreover, there exist serious consequences when movies adapted based on literature texts are shown to students, that is, for every reader, rich imagery of literature and the literary character are finally set. Faced with same literary works, "There are a thousand Hamlets in a thousand people's eyes", but playing associated audio and video will cause reader to accept same mold, which kills imagination of readers.

\subsection{Too much media elements undermine perception of texts}

Literature is an art of language, which adopts permutations and combinations of texts, various practices of performance, rhetoric, and specific context setting, simple expression of infinite significance of texts. Obviously, an inescapable teaching objective of literature courses is to allow students to understand charm of Chinese language through analysis of thoughts and behavior of characters, ups and downs of plots, contradictory tangle and beyond such text feeling. But due to too much media involvement into literary teaching language, expression of words seems to be impotent. Therefore, in such literature courses teaching 
classroom, students feel more strong impact of images, sounds and graphics, to some extent ignores existence of language.

\subsection{Misunderstanding of courseware leads to lack of charisma education}

Courseware is core of CAI system, which is formulated by courseware designers according to teaching requirement by means of CAI writing tools or computer program language. It should be mentioned that there is direct correlation between quality of courseware production and effectiveness of CAI teaching. For many teachers of literature course, however, there presently exist deviations from courseware understanding. In teaching activities, too much relying on courseware, more badly, task of classroom will be equivalent to displaying of exquisite courseware. With the help of traditional teaching methods, teachers can attract attention of students through their own beautiful calligraphy writing, reading articles in cadence, amusing interpretation of body language and explanation language of classroom, which form a strong magnetic field of personality. In the current CAI, teachers usually take a back seat near computer, while various software tools are expanding whole thread but lack of interpretation of human nature. And in this case, teachers habitually enslave servants for computer, in other words, a whole class will usually not be left from computer, which breaks good interaction formed between students and teachers.

\subsection{Limited level of courseware production causes worse effectiveness of teaching}

Because of excessive exhibition of media means, teachers are more concerned with how to make courseware more beautiful in its production, and more attractive, to some extent weaken the transmission of teaching goal. Surrounded with dazzling images, audio, video and other information, students are not inclined to grasp key of teaching. In addition, teachers engaged in literature courses teaching mostly know very little about development and application of computer software. Often in the courseware production, word version of the texts is pasted directly into PowerPoint, or text is mechanically hyper-linked course content with images, audio and video clips. This production of courseware is no different from the traditional mode of classroom teaching on a blackboard to playing in PowerPoint. Although this playing save more time than traditional way of teaching with writing on blackboard, and increasing more information of class, too fast speed of playback makes it impossible of students recording down main content as reference for future review.

\section{Discussion of Impovment of Litterature Course Teaching Effectiveness Using Computer Aided Instruction}

Authentic CAI regards computer and multimedia language as tools, achieving the "dialogue" among teacher and students referred as ultimate goal of teaching. CAI multimedia classroom system only provides teachers with application environment, how to realize ultimate "dialogue" has become an important issue to be addressed in design of teaching content. Thus, oriented with the CAI, the teacher is still dominant in teaching activities, whether or not improvement of teaching effectiveness is also being completely under control of teachers. At this point, author started on the following superficial discussion of this topic.

\subsection{Design of multimedia elements based on understanding characteristics of Literature Courses}

As the saying goes, "knowing oneself and the other side is undefeated in many battles". Same as a teaching activity itself, but also characteristics of course must be first understood, and then creating their own courseware to gain a multiplier effect. The literature curriculum mainly makes readers to appreciate realm of Chinese language through each one arrangement combination of writing, as well as beauty of character of story and profound emotion of author's thought and so on. To realize this type of teaching, texts of literary works must take a place in design of courseware, and can not be replaced completely by animation, audio, video and 
other information. Without a doubt, whole class also could not be exhibited only by texts, which clearly loses real meaning of multimedia classroom system. In literary classroom, prime display object is language texts, and other applications of multimedia language are designed to enrich and to present visualization of abstract language as necessary supplement. That is to say, when teacher parses details of a literature works, he (she) should firstly present its texts in PowerPoint for students fully perceiving expression of text language.

In this context, in order to understand thoughts and feelings brought by texts of a paragraph, volatility of inner world of characters and background information behind of article, students can be visually tasted through audio, video materials or TV drama adaptation of this work. Therefore, students naturally do not equal literary works with film and TV products because texts information has be shown prior to playing multimedia elements. In the process of acceptance, students will unconsciously compare expression and skills of presentation between literature language and film and TV products language. They would naturally perceive and sense expression of infinite tension and provision of rich imagination of texts language, which file and TV products could not have these capabilities. As an end, applications and design of multimedia language can cause literary courses return to literature and text itself, allowing students to wander in the limitless charm of language.

\subsection{Retrival of dominant position of teachers in the classroom teaching}

In CAI method, teacher is still dominant of teaching activity, and not only operator of computer and courseware but also head director of whole class process. In the CAI, teacher is not limited to standing near computer or podium of three feet, whereupon he completes slides turning, full-screen playing, blank screen and other operation control of general functions, using a wireless remote controller of PPT. While teachers freely standing can effectively avoid reading content according to screen, and also can make necessary supplement of teaching content or extension explanation according to reflect of students. When doing that, teacher can also have appropriate participation of humor, body language. These teachers with aforementioned characteristics will have good affinity, and then such active atmosphere of class can make effectiveness of acceptance be the best.

In addition, extensive usage of images, animation, audio, video and other media is not purpose for purely operating machine like a wooden puppet in class to teacher, but fully displaying personal charisma on the basis of their expertise. Such as a certain teacher's voice is very magnetic, and good at reading, singing or acting, in this context, there is no need to introduce others audio or video clips through multimedia presentations, but should become a class of displaying charisma of teachers. This show of interaction among people is more attractive than dead machine. Fully display of charm of this character not only can activate both classroom atmosphere, but also greatly mobilizes enthusiasm of students imitating, achieve purpose of educating people through teaching. In such CAI, class atmosphere can be fully active, teacher can fully display themselves, students also can express their ideas, thus teachers and students can perfectly complete "dialogue."

\subsection{Efficient courseware production in line with combination of multimedia technologies and literature courses features}

"Courseware production involves many disciplines of knowledge and skills, generally speaking, curriculum specialists, instructional designers, psychologists, experienced academic teachers, educational researchers, art people, software designers, and sometimes, musicians, staffs of video recording and etc participate jointly, organizing courseware development team. So a good courseware need variety of factors integrated." [4]. Flow of courseware production is drawn in Fig 1.

However, at present, in the actual teaching of literature courses, teachers often directly in CAI writing system (usually present in the PowerPoint) link animation, audio, video clips to text contents in light of their understanding of teaching content and grasp of computer software. Specifically, there are few teachers not familiar with computer software, directly downloading courseware from public network, even making not any changes. Effect of such courseware can be imagined. It should be said that current multimedia technology for 
many lazy teacher provides convenience. But in fact, really designing and developing courseware, teachers actually spend more time and energy than hard traditional teaching methods. Teachers producing courseware are not only psychologist, technical experts and photographer, but also people being familiar with teaching content. For literature courses teaching, really good courseware must be organic integration of computer media technology and tension of expression of text body. In short, any either can not be neglected.

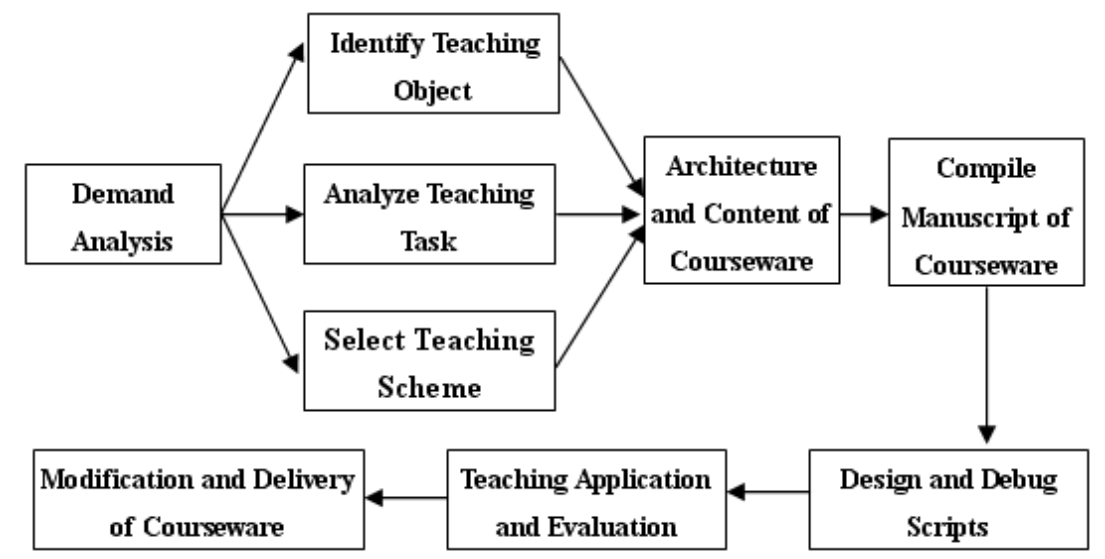

Fig. 1. Flow of courseware production

\section{Conclusions}

E.G Berg [5], American scholar, pointed out that "The impact of new technologies on the universities is still a developing theme of mission of higher education. Impact of computer, information and communication technologies on the universities has not been fully demonstrated. However, from the early development of the current very superficial point of view, we have already noted, higher education is undergoing major structural changes. History tells us that in this progress there must be some side effects of depressing to consider ..." As a matter of fact, for any excellent teaching tools and means, there is a rational and effective usage problem. We can not completely ignore new technology itself because of emergence of temporary problems. We have every reason to believe that, with teachers deeply understanding of computer-aided teaching and continuously exploring of education practices, in teaching of literature courses, CAI can assuredly obtain desirable results.

\section{References}

[1] D. Collins, A.Deck, M. McCrickard, "Computer Aided Instruction: A Study of Student Evaluations and Academic Performance," J. of College Teaching \& Learning, vol. 5, No.11, 2008,pp. 49-58

[2] C. X. Bai, C.G. Liang, "Impact of multimedia technology on teaching process of university," J. of Tianjin Manager College, vol. 3, 2007, pp. 41-42. (in Chinese )

[3] X. L. Guo, "My opinion on multimedia teaching of university," Continue Education Research, vol. 5, 2009, pp. 119-120.(in Chinese )

[4] S. L. Wang, "Research on courseware production," J. of Jiangsu Teachers University of Technology, vol. 12, 2007, pp. 61-64. (in Chinese)

[5] E.G. Berg, "Pursuing the soul of American higher education," Fudan Education Forum, vol. 1, 2004, pp. 69-71. 